\title{
Radiosurgery for multiple sclerosis-related trigeminal neuralgia: retrospective review of long-term outcomes
}

\author{
Colin J. Przybylowski, MD, Tyler S. Cole, MD, Jacob F. Baranoski, MD, Andrew S. Little, MD, \\ Kris A. Smith, MD, and Andrew G. Shetter, MD \\ Department of Neurosurgery, Barrow Neurological Institute, St. Joseph's Hospital and Medical Center, Phoenix, Arizona
}

\begin{abstract}
OBJECTIVE The objective of this study was to assess long-term outcomes of facial pain and numbness after radiosurgery for multiple sclerosis (MS)-related trigeminal neuralgia (MS-TN).

METHODS The authors conducted a retrospective review of their Gamma Knife radiosurgeries (GKRSs) to identify all patients treated for MS-TN (1998-2014) with at least 3 years of follow-up. Treatment and clinical data were obtained via chart review and mailed or telephone surveys. Pain control was defined as a facial pain score of I-IIllb on the Barrow Neurological Institute (BNI) Facial Pain Intensity Scale. Kaplan-Meier analysis was performed to determine the rates of pain control after index and first salvage GKRS procedures. Patients could have had more than 1 salvage procedure. Pain control rates were based on the number of patients at risk during follow-up.
\end{abstract}

RESULTS Of the 50 living patients who underwent GKRS, 42 responded to surveys (31 women [74\%], median age 59 years, range 32-76 years). During the initial GKRS, the trigeminal nerve root entry zone was targeted with a single isocenter, using a 4-mm collimator with the $90 \%$ isodose line completely covering the trigeminal nerve and the $50 \%$ isodose line abutting the surface of the brainstem. The median maximum radiation dose was $85 \mathrm{~Gy}$ (range 50-85 Gy). The median follow-up period was 78 months (range 36-226 months). The rate of pain control after the index GKRS ( $n=42)$ was $62 \%, 29 \%, 22 \%$, and $13 \%$ at $1,3,5$, and 7 years, respectively. Twenty-eight patients $(67 \%)$ underwent salvage treatment, including $25(60 \%)$ whose first salvage treatment was GKRS. The rate of pain control after the first salvage GKRS $(n=25)$ was $84 \%, 50 \%, 44 \%$, and $17 \%$ at $1,3,5$, and 7 years, respectively. The rate of pain control after the index GKRS with or without 1 salvage GKRS $(n=33)$ was $92 \%, 72 \%, 52 \%, 46 \%$, and $17 \%$ at $1,3,5,7$, and 10 years, respectively. At last follow-up, 9 (21\%) of the 42 patients had BNI grade I facial pain, $35(83 \%)$ had achieved pain control, and $4(10 \%)$ had BNI grade IV facial numbness (very bothersome in daily life).

CONCLUSIONS Index GKRS offers good short-term pain control for MS-TN, but long-term pain control is uncommon. If the index GKRS fails, salvage GKRS appears to offer beneficial pain control with low rates of bothersome facial numbness.

https://thejns.org/doi/abs/10.3171/2018.5.JNS173194

KEYWORDS facial numbness; facial pain; Gamma Knife; multiple sclerosis; stereotactic radiosurgery; trigeminal neuralgia

$\mathrm{M}$ ULTIPLE sclerosis (MS)-related trigeminal neuralgia (MS-TN) is a severe and disabling pain disorder affecting approximately $1 \%-2 \%$ of patients with MS. ${ }^{4}$ MS-TN is believed to be related to demyelination of the trigeminal nerve root entry zone and is more challenging to manage than idiopathic TN. ${ }^{1,6,7,11,16}$

The progressively disabling neurological symptoms of MS make it difficult for patients with MS-TN to tolerate invasive procedures and the adverse effects of medications. Thus, radiosurgery is a preferred treatment option for these patients because of its low incidence of adverse effects. Pain control outcomes after radiosurgery for MSTN appear favorable in the short term, but long-term outcomes have not been thoroughly investigated..$^{13,16,18}$ The objective of this study was to determine long-term facial pain and numbness outcomes after radiosurgery for MS-TN.

ABBREVIATIONS BNI = Barrow Neurological Institute; GKRS = Gamma Knife radiosurgery; $m R S=$ modified Rankin Scale; MS = multiple sclerosis; MS-TN = MS-related trigeminal neuralgia; $\mathrm{MVD}=$ microvascular decompression; $\mathrm{TN}$ = trigeminal neuralgia.

SUBMITTED December 21, 2017. ACCEPTED May 31, 2018.

INCLUDE WHEN CITING Published online November 30, 2018; DOI: 10.3171/2018.5.JNS173194. 


\section{Methods \\ Patient Selection}

This study was conducted with the approval of the IRB of St. Joseph's Hospital and Medical Center. We retrospectively reviewed the Gamma Knife radiosurgery (GKRS) database at our institution to identify all patients treated for MS-TN between January 1, 1998, and March 1, 2014. This time frame ensured that all patients would have had at least 3 years of clinical follow-up duration at the time of analysis. The senior authors (K.A.S. and A.G.S.) analyzed records from the patients' initial neurosurgical consultation and confirmed the diagnosis of MS-TN based on the diagnostic criteria delineated by Eller et al. in which "symptomatic TN" is a direct result of MS. ${ }^{2}$ We used the STROBE (Strengthening the Reporting of Observational studies in Epidemiology) guidelines for cohort studies as the reporting guidelines for this study (http://www.strobestatement.org).

\section{GKRS Technique}

Various models of the Leksell Gamma Knife (Elekta) were used to treat patients over the study period: the Model B unit in 1998-2002, the Model C unit in 2003-2007, and the Perfexion in 2008-2014. Stereotactic MRI or CT cisternography was performed with the stereotactic frame before the procedure. A $0.4-\mathrm{mm}$ grid matrix was centered over the trigeminal nerve at the root entry zone. A single 4-mm collimator shot was then positioned so that the $90 \%$ isodose line completely covered the trigeminal nerve and the $50 \%$ isodose line just abutted the surface of the brainstem.

\section{Follow-Up and Outcome Measurements}

Patients were followed clinically by the neurosurgeon and primary neurologist. If the index GKRS failed, the patient typically underwent 1 or more salvage GKRS treatments. If the patient had no clinical response to salvage GKRS, other therapies such as rhizotomy or microvascular decompression (MVD) may have been used. To determine long-term outcomes, we mailed standardized surveys to each patient on March 6, 2017. ${ }^{8}$ The Barrow Neurological Institute (BNI) Facial Pain Intensity Scale ( $\mathrm{I}=$ no pain, no pain medication; $\mathrm{II}=$ occasional pain not requiring medication; IIIa = no pain, but continued taking medication for fear of stopping; IIIb = continued pain, adequately controlled with medication; IV = some pain, not adequately controlled with medication; and $\mathrm{V}=$ severe pain or no pain relief) and the BNI Facial Numbness Scale ( $\mathrm{I}=$ none, $\mathrm{II}=$ not bothersome, III = somewhat bothersome, and IV = very bothersome) were used to grade outcomes. ${ }^{8,12}$ Pain control was defined as maintaining a facial pain score of I-IIIb, and treatment failure was defined as reaching a pain score of IV or $\mathrm{V}$ or requiring repeat intervention as previously described. ${ }^{8}$ These definitions were applied to all analyses, including those for salvage GKRS. Patients who did not respond to mailed surveys or who provided vague responses on them were contacted by telephone for follow-up interviews. Demographic and treatment characteristics were collected via retrospective chart review.

\section{Statistical Analysis}

All statistical analyses were performed using R statistical software ( $R$ Foundation for Statistical Computing; https://www.r-project.org). The survival package in $\mathrm{R}$ was used for the survival analysis. Kaplan-Meier analysis was used to calculate the actuarial time to treatment failure for the index and salvage GKRS procedures. Univariate analysis was then performed to identify the predictive factors among collected variables. For categorical variables, the Fisher exact test was used. For continuous variables, the Mann-Whitney U-test was used. All p values $<0.05$ were considered statistically significant.

\section{Results}

\section{Patient Enrollment and Characteristics}

Our search of the Gamma Knife database identified 55 patients who met the inclusion criteria. Five patients were determined to have died prior to initiation of the study and were excluded. Of the 50 patients who were mailed surveys, 30 patients responded. Of the 20 patients who did not respond to mailed surveys, 12 were contacted for telephone surveys. Eight patients (16\%) were lost to followup. The CONSORT (Consolidated Standards of Reporting Trials) flow diagram is presented in Fig. 1.

Patient characteristics are summarized in Table 1. The median patient age at the time of diagnosis with MS and at the time of the index GKRS was 42 years (range 18-66 years) and 59 years (range 32-76 years), respectively. Thirty-one $(74 \%)$ of the 42 patients were female, and $11(26 \%)$ were male. The side with facial pain that was treated was the left side in 22 patients $(52 \%)$. The most common distribution of pain was $\mathrm{V}_{3}$ (18 patients, 43\%). Eight patients (19\%) reported some degree of preradiosurgery facial numbness. The median preradiosurgery modified Rankin Scale (mRS) score was 2 (range 0-5). The median clinical follow-up period was 78 months (range 36-226 months).

\section{Index GKRS}

The median maximum radiation dose was $85 \mathrm{~Gy}$ (range 50-85 Gy). A maximum dose of 85 Gy was used in most of the 42 patients (32 patients, $76 \%$ ). Treatment failure from the index GKRS occurred in 34 patients (81\%) at a median time to failure of 16 months (range 1-84 months). Figure 2 shows the survival curve for pain control after the index GKRS $(n=42)$. The actuarial rate of pain control at 1,3,5, and 7 years based on the number of patients at risk during follow-up was $62 \%, 29 \%, 22 \%$, and $13 \%$, respectively. Three patients $(7 \%)$ achieved a BNI grade I pain score after the index GKRS and never required salvage therapy. We analyzed whether any characteristics of patients or any treatment factors (e.g., demographics, treatment dose, pain location, facial numbness) were predictive of pain control after treatment, and we found no statistically significant predictors.

\section{Salvage Therapy}

Salvage therapies are listed in Table 2. Twenty-eight $(67 \%)$ of the 42 patients underwent salvage therapy over the study period at a median of 13 months (range 2-84 


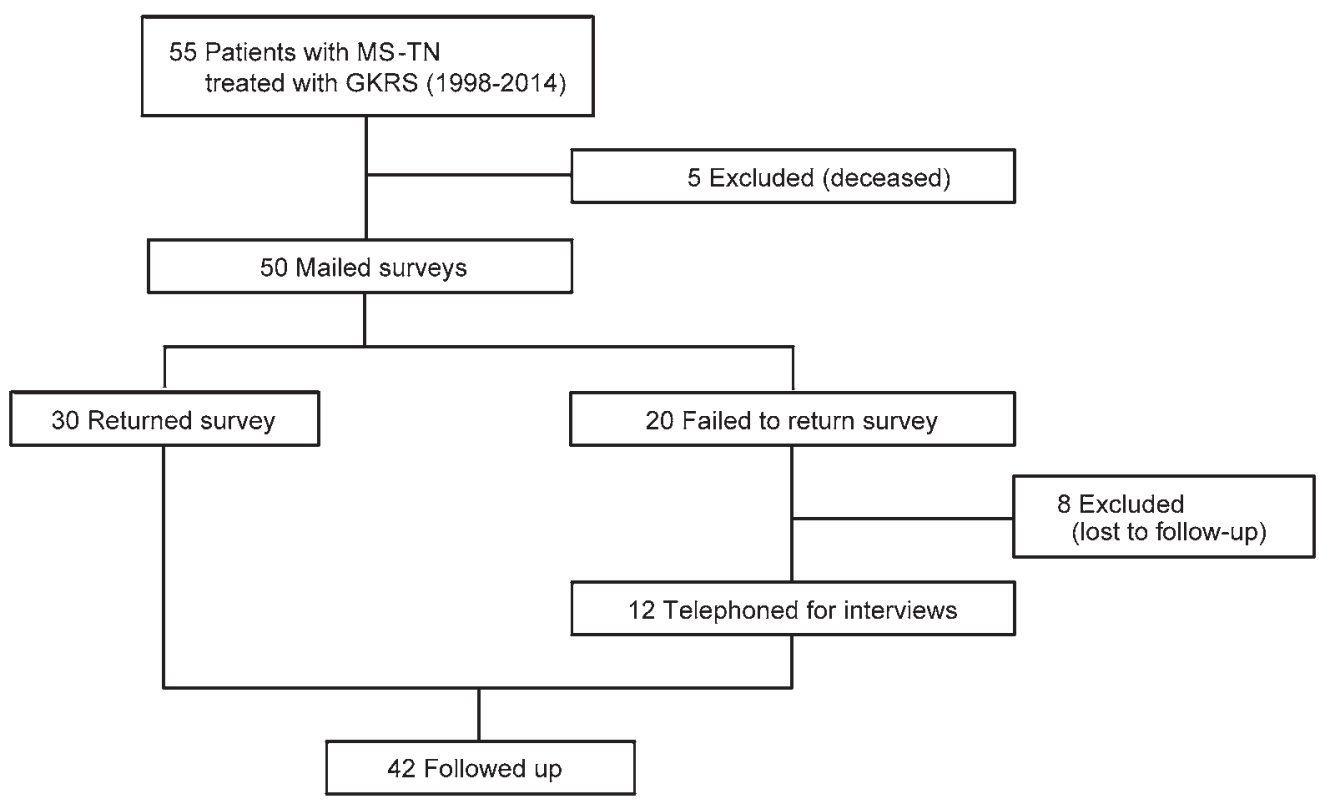

FIG. 1. CONSORT flowchart.

months) after the first treatment. This includes patients who had no response to the initial GKRS. Typically, we waited at least 2 months to see if the patients had a positive response to the initial GKRS, in conjunction with medication adjustments. Patients were thereafter considered for salvage treatment if they never reached a BNI pain score of IIIb or if their pain level at any point regressed beyond IIIb. GKRS alone was the most common salvage treatment $(\mathrm{n}=18,43 \%)$. For salvage GKRS, all patients received a maximum radiation dose of $50 \mathrm{~Gy}$. Glycerol rhizotomy and MVD were used alone only once each. After salvage GKRS failed for 7 patients, $5(12 \%)$ underwent thermal rhizotomy and 2 patients $(5 \%)$ underwent MVD. One patient underwent MVD, followed by glycerol rhizotomy and subsequent GKRS. Thus, 25 (74\%) of 34 patients with pain recurrence underwent GKRS as their initial salvage therapy. Figure 3 shows the survival curve for pain control from the initial salvage GKRS $(n=25)$. For this analysis, time point zero was the time of the salvage GKRS. The actuarial rate of pain control at 1,3,5, and 7 years based on the number of patients at risk during follow-up was $84 \%, 50 \%, 44 \%$, and $17 \%$, respectively. The median time to treatment failure was 29 months (range $0-115$ months). The difference in pain control between the index and salvage GKRS procedures was not statistically significant $(\mathrm{p}=0.11)$. Lastly, we sought to analyze the rates of pain control when the initial salvage GKRS was considered part of the original treatment strategy, consistent with our typical clinical practice. Figure 4 shows the survival curve for pain control from the index GKRS with and without 1 salvage GKRS $(n=33)$. In this analysis, treatment was not considered to have failed until the pain score reached IV or $\mathrm{V}$ after a salvage GKRS procedure. The actuarial rate of pain control at 1,3,5,7, and 10 years based on the number of patients at risk during follow-up was $92 \%, 72 \%, 52 \%$,
$46 \%$, and $17 \%$, respectively. The median time to treatment failure was 78 months (range 1-96 months).

\section{Final Facial Pain and Numbness Outcomes}

Patients were taking a median of 1 pain medication

TABLE 1. Characteristics of 42 patients with MS-TN

\begin{tabular}{|c|c|}
\hline Variable & Value \\
\hline \multicolumn{2}{|l|}{ Median age (range), yrs } \\
\hline Diagnosed with MS & $42(18-66)$ \\
\hline Index GKRS & $59(32-76)$ \\
\hline \multicolumn{2}{|l|}{ Sex, no. $(\%)$} \\
\hline Female & $31(74)$ \\
\hline Male & $11(26)$ \\
\hline \multicolumn{2}{|l|}{ Side of pain, no. (\%) } \\
\hline Lt & $22(52)$ \\
\hline Rt & $20(48)$ \\
\hline \multicolumn{2}{|l|}{ Distribution of pain, no. (\%)* } \\
\hline$V_{1}$ & $2(5)$ \\
\hline$V_{2}$ & $6(14)$ \\
\hline$V_{3}$ & $18(43)$ \\
\hline$V_{1+2}$ & $4(10)$ \\
\hline$V_{1+3}$ & $2(5)$ \\
\hline$V_{2+3}$ & $8(19)$ \\
\hline$V_{1+2+3}$ & $2(5)$ \\
\hline Pre-GKRS facial numbness, no. (\%) & $8(19)$ \\
\hline Pre-GKRS mRS score (range) & $2(0-5)$ \\
\hline Mean follow-up (range), mos & $78(36-226)$ \\
\hline
\end{tabular}




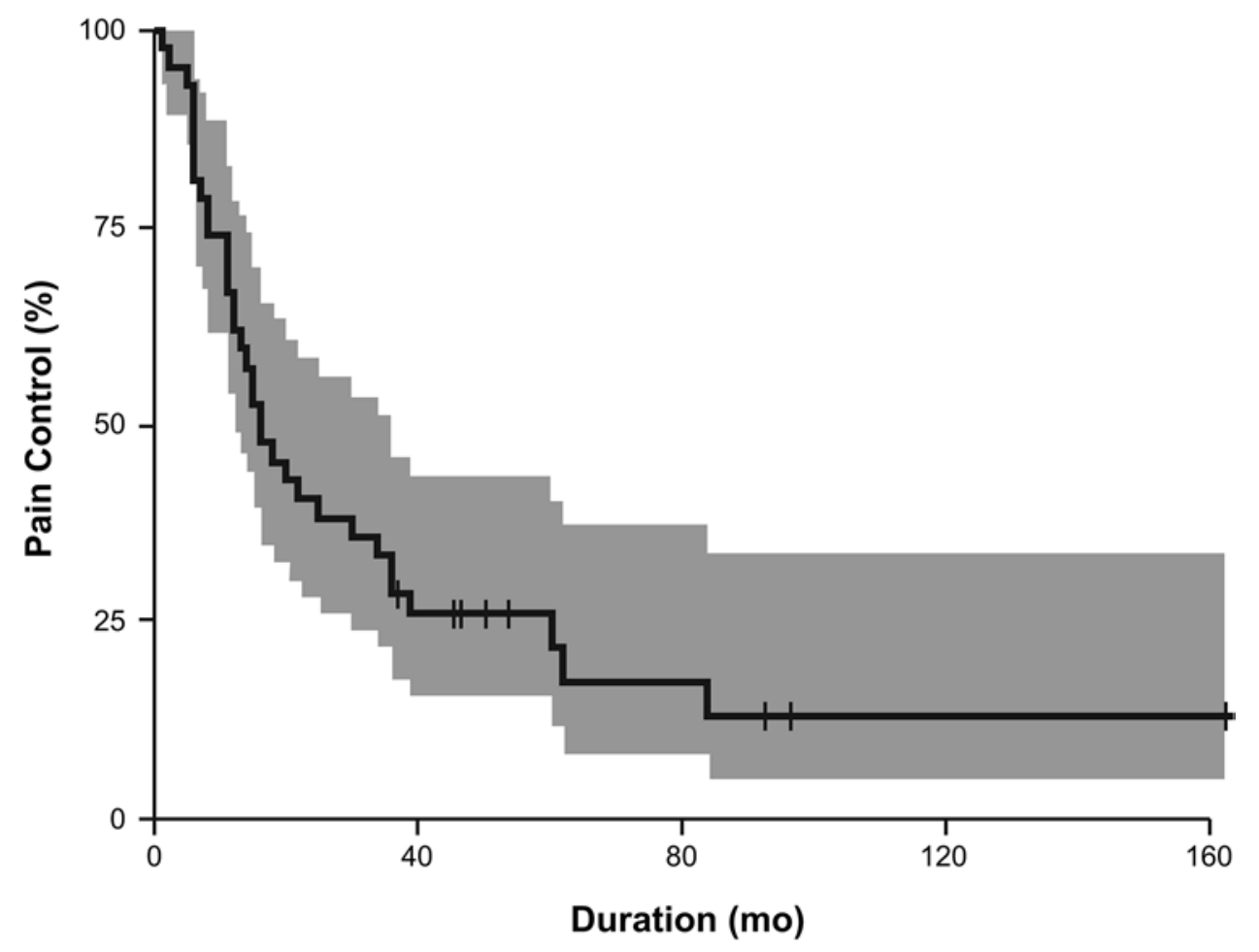

\begin{tabular}{ccccc}
\hline $\begin{array}{c}\text { Follow-up } \\
\text { period (mo) }\end{array}$ & $\begin{array}{c}\text { No. } \\
\text { at risk }\end{array}$ & $\begin{array}{c}\text { No. } \\
\text { of events }\end{array}$ & $\begin{array}{c}\text { No. } \\
\text { censored }\end{array}$ & $\begin{array}{c}\text { Pain control } \\
(\%)\end{array}$ \\
\hline 12 & 28 & 16 & 0 & 62 \\
36 & 14 & 14 & 0 & 29 \\
60 & 6 & 2 & 5 & 22 \\
84 & 4 & 2 & 0 & 13 \\
120 & 1 & 0 & 2 & 13
\end{tabular}

FIG. 2. Kaplan-Meier analysis of pain control (BNI grades I-IIIb) after index GKRS in 42 patients. Shaded areas indicate $95 \%$ confidence interval estimates. Hash marks indicate standard right censoring.

(range 0-3 pain medications) at last follow-up. Figure 5 shows the outcomes of the final facial pain score stratified by salvage therapy. At last follow-up, 35 (83\%) of the 42 pa-

TABLE 2. Salvage therapies after index GKRS for MS-TN

\begin{tabular}{cc}
\hline \multicolumn{1}{c}{ Therapy } & No. $(\%)^{*}$ \\
\hline Repeat GKRS only & $18(43)$ \\
\hline 1 repeat GKRS & $11(26)$ \\
\hline 2 repeat GKRS & $5(12)$ \\
\hline 3 repeat GKRS & $1(2)$ \\
\hline 4 repeat GKRS & $1(2)$ \\
\hline Glycerol rhizotomy only & $1(2)$ \\
\hline MVD only & $1(2)$ \\
\hline Repeat GKRS + thermal rhizotomy & $5(12)$ \\
\hline Repeat GKRS + MVD & $2(5)$ \\
\hline MVD + glycerol rhizotomy + repeat GKRS & $1(2)$ \\
\hline
\end{tabular}

* Twenty-eight ( $67 \%)$ of 42 patients underwent salvage therapy after the index GKRS. tients reported pain control, and 9 patients $(21 \%)$ had a BNI grade I pain score. Table 3 summarizes the final outcomes for the facial numbness scores. At last follow-up, 4 patients $(10 \%)$ reported very bothersome facial numbness (grade IV), 3 of whom had received at least 2 GKRS treatments.

\section{Discussion}

MS-TN is a disabling pain disorder that is challenging to manage. The pathogenesis of MS-TN and the morbidity associated with invasive intervention make the traditional surgical options used for idiopathic TN less appealing in the MS population. Specifically, because vascular compression is typically not associated with MS-TN, the role of MVD, which has excellent success rates in idiopathic TN, is limited in MS-TN. ${ }^{11}$ Radiosurgery is the first-line treatment for MS-TN at our institution because of its minimally invasive nature, low incidence of adverse effects, and the fact that it does not preclude more invasive treatments that might be needed. In this study, we aimed to determine long-term facial pain and numbness outcomes after GKRS for MS-TN. 


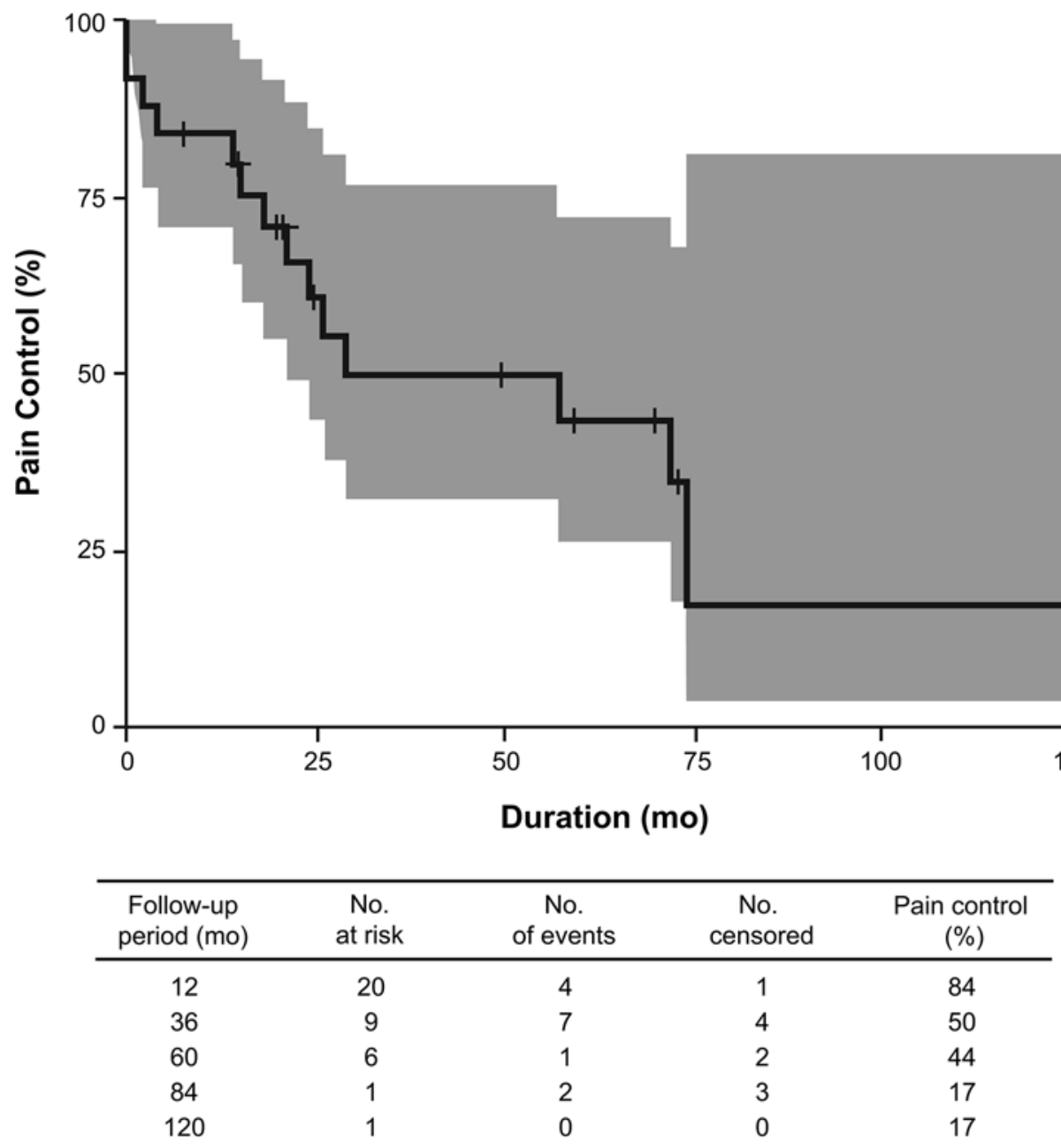

FIG. 3. Kaplan-Meier analysis of pain control (BNI grades I-IIIb) after salvage GKRS in 25 patients. Shaded areas indicate $95 \%$ confidence interval estimates. Hash marks indicate standard right censoring.

Our results show that the index GKRS procedure offers acceptable short-term pain control for MS-TN but often fails to provide long-term pain control when used alone. Freedom from pain off medication after the index GKRS was rare in our cohort (3 of 42 patients; 7\%). Nonetheless, good long-term pain control can be achieved with multimodal therapy. Overall, the incidence of bothersome facial numbness is low. Our study confirms the commonly held belief that the success rate of radiosurgery for MSTN is significantly lower than that for idiopathic TN. Little et al. ${ }^{8}$ used a similar methodology to evaluate our institutional experience with radiosurgery for idiopathic $\mathrm{TN}$ and found that the long-term pain control rate was $63 \%$ at 7 years. Additionally, at last follow-up (7 years), 32\% of patients had achieved freedom from pain off medication. The reason for this discrepancy is unclear, but it may reflect a different etiology for MS-TN or the fact that MS is a progressive neurodegenerative process.

Relatively few authors have reported on the effectiveness of radiosurgery for MS-TN. In 2002, Huang et al. ${ }^{5}$ and Rogers et al. ${ }^{13}$ reported low rates of pain recurrence (14\% [1 of 7] and 33\% [5 of 15], respectively), but these 2 series were significantly limited by their small sample size and by a short follow-up period (median 28 months and mean 17 months, respectively). In 2009, Zorro et al. ${ }^{18}$ reported the outcomes for 37 patients treated with radiosurgery for MS-TN with a minimum follow-up of 6 months. They reported a pain recurrence rate of $38 \%(\mathrm{n}=14)$ at a median follow-up period of 56.7 months. In 2014, Weller et al. ${ }^{16}$ reported a pain recurrence rate of $18 \%$ ( 6 of 33 patients) with a median follow-up period of 39.2 months but included patients with only 3 months of follow-up. Also in 2014, Tuleasca et al..$^{14}$ reported a pain recurrence rate of $61.5 \%$ (24 of 39 initially pain free after the index radiosurgery) in 43 patients with a median follow-up period of 53.8 months and a minimum follow-up of 12 months.

Previous studies have been substantially limited by the duration of follow-up. In our series and in the series by Tuleasca et al., ${ }^{14}$ which are the 2 largest series in the medical literature, the median time to pain recurrence after the index radiosurgery was 16 months. Yet, previous studies have included patients with $\leq 12$ months of minimum clinical follow-up time, which may have resulted in overestimation of radiosurgical pain control rates. The 


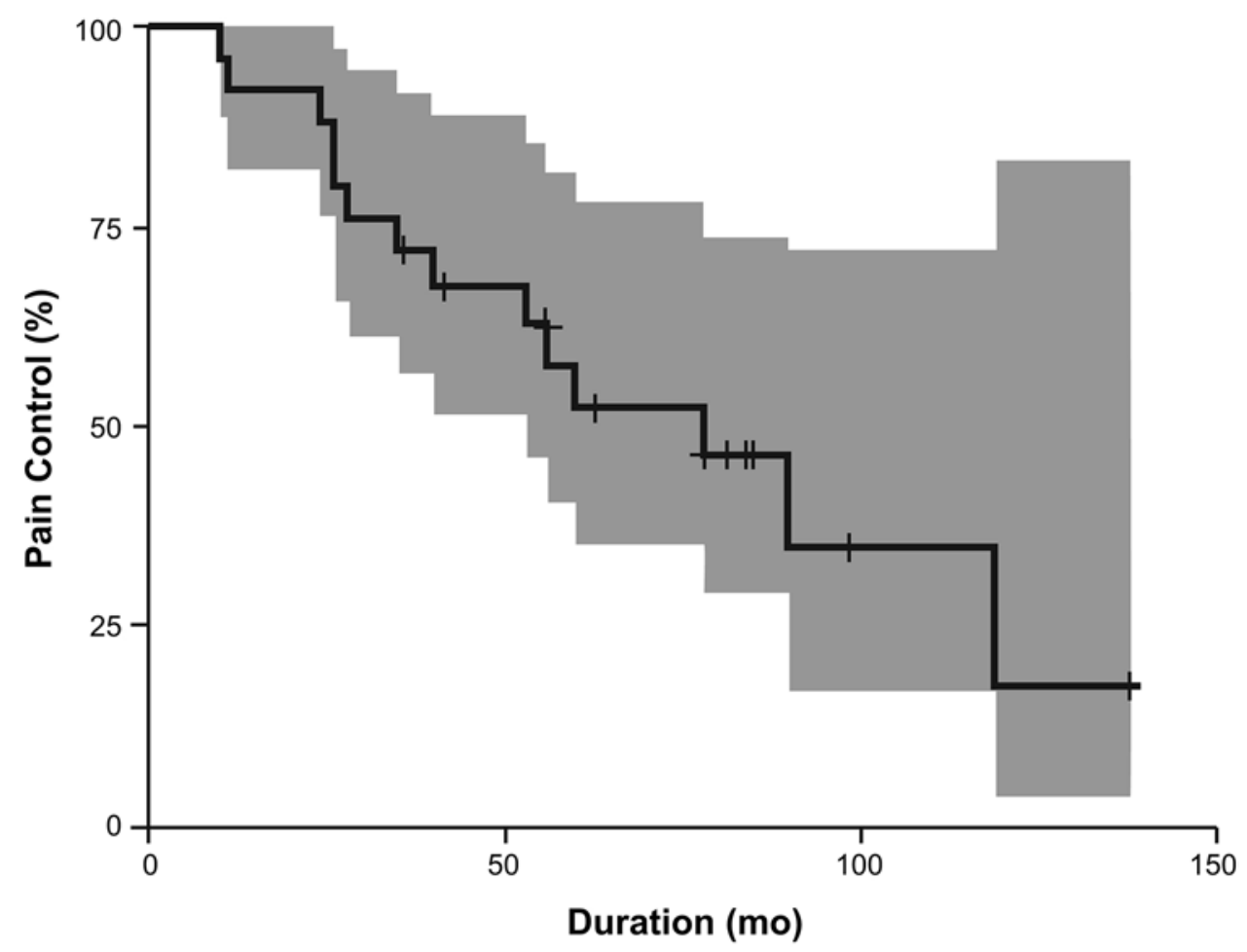

\begin{tabular}{ccccc}
\hline $\begin{array}{c}\text { Follow-up } \\
\text { period (mo) }\end{array}$ & $\begin{array}{c}\text { No. } \\
\text { at risk }\end{array}$ & $\begin{array}{c}\text { No. } \\
\text { of events }\end{array}$ & $\begin{array}{c}\text { No. } \\
\text { censored }\end{array}$ & $\begin{array}{c}\text { Pain control } \\
(\%)\end{array}$ \\
\hline 12 & 23 & 2 & 0 & 92 \\
36 & 16 & 5 & 2 & 72 \\
60 & 11 & 4 & 2 & 52 \\
84 & 5 & 1 & 4 & 46 \\
120 & 1 & 2 & 2 & 17
\end{tabular}

FIG. 4. Kaplan-Meier analysis of pain control (BNI grades I-IIlb) after index GKRS with and without 1 salvage GKRS in 33 patients. Shaded areas indicate $95 \%$ confidence interval estimates. Hash marks indicate standard right censoring.

published actuarial rates of pain control from the index radiosurgery range from $57 \%$ to $82 \%$ at 1 year, to $38 \%-54 \%$ by 5 years. ${ }^{14,16,18}$ This drop in efficacy in the first 5 years after treatment is in agreement with our results. Our 1- and 5 -year pain control rates were $62 \%$ and $22 \%$, respectively (Fig. 2).

Although the difference in pain control between the index and salvage radiosurgeries was not statistically significant $(\mathrm{p}=0.11)$, our experience with idiopathic TN indicates that the index radiosurgery is more effective than the salvage radiosurgery for facial pain control. ${ }^{8}$ We also performed a third analysis on the pain control rates when the first salvage GKRS was considered part of the initial treatment strategy. Doing so allowed for a practical analysis of our standard clinical practice. When an initial salvage GKRS was considered part of the treatment plan, we found the pain control rate at 1,5 , and 7 years based on the number of patients at risk during follow-up was $92 \%$, $52 \%$, and $46 \%$, respectively. Thus, patients with MS-TN do appear to benefit clinically from salvage radiosurgery. For salvage radiosurgery, we treat with a maximum radiation dose of $50 \mathrm{~Gy}$, which is at the low end reported in the medical literature for recurrent TN. ${ }^{10,15}$ We consider this approach to be an acceptable compromise between achieving pain control and preventing facial numbness. In our opinion, if the treatment goal is to achieve facial numbness, rhizotomy is a better option than radiosurgery because the numbness can be graded and confined to the trigeminal divisions with pain.

The low morbidity associated with radiosurgery is particularly important in a patient population with a degenerative neurological disorder. The rare but serious complications associated with MVD such as infection, CSF leak, and death do not occur after radiosurgery. Mathieu et al. ${ }^{9}$ compared the results for radiosurgery $(\mathrm{n}=27)$ and glycerol rhizotomy $(n=18)$ to treat MS-TN and found a higher rate of facial numbness in the rhizotomy group $(61 \%, \mathrm{n}=$ 11 ) than in the radiosurgery group $(22 \%, \mathrm{n}=6)$. Adverse effects of rhizotomy also included loss of corneal reflex in 2 patients and bacterial meningitis in 1 patient. No radiosurgery studies for MS-TN have shown any significant complications beyond facial numbness. Specifically, worsening MS symptoms, trigeminal weakness, keratitis, infection, hearing impairment, and facial nerve palsy af- 


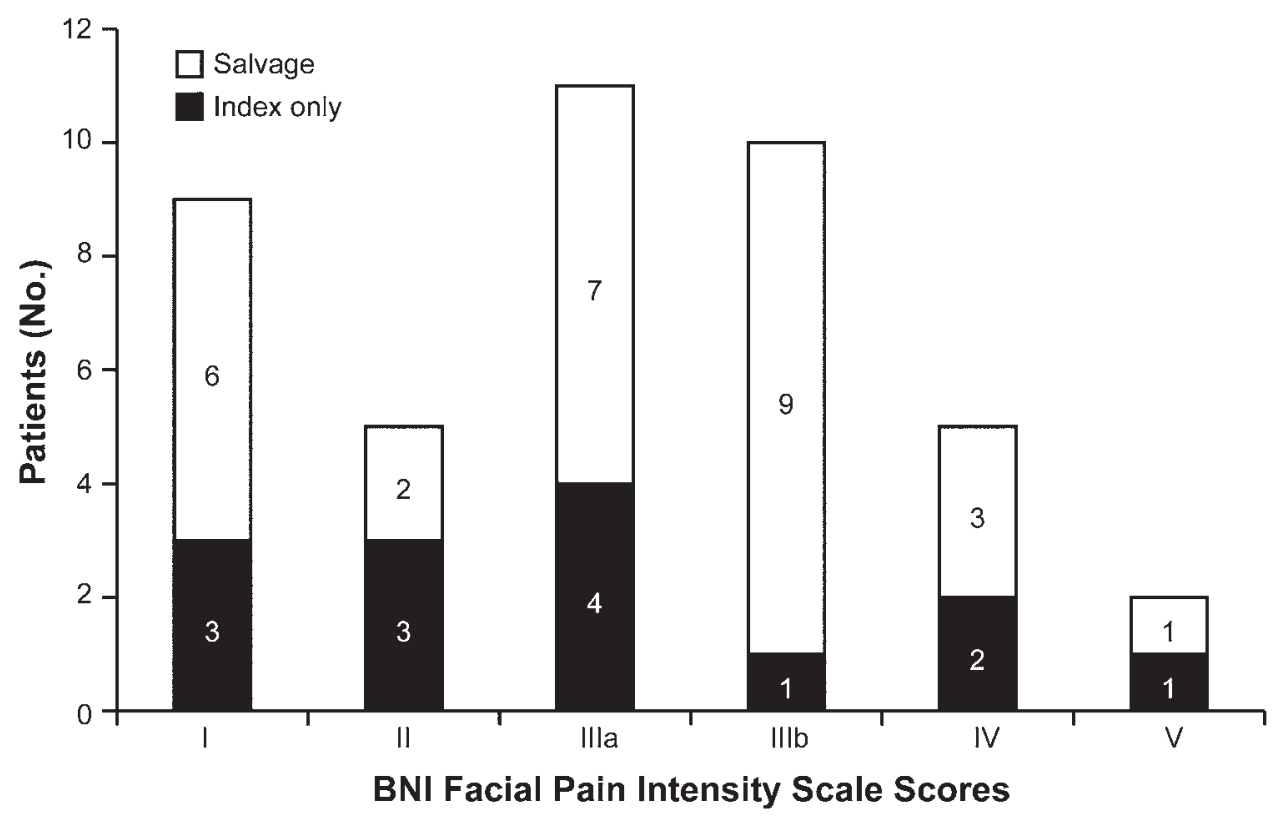

FIG. 5. BNI pain intensity scores of 42 patients with MS-TN treated with GKRS at last follow-up (median 78 months). The number of patients in each pain score category is stratified by use or nonuse of salvage therapy.

ter treatment have not been reported in other radiosurgery series and were not observed in our study. $.9,13,14,16,18$

The incidence of facial numbness after radiosurgery for MS-TN ranges widely in the medical literature, from 5\% to $57 \%$, but facial numbness that affects quality of life is rare. ${ }^{5,14,16,18}$ Four patients (10\%) in our series reported very bothersome facial numbness. This rate is higher than that reported in the literature and is likely a result of our long follow-up period and high rate of salvage therapy. Our decision to not use multiple shots for the initial radiosurgery procedure was based on the work by Flickinger et al. ${ }^{3}$ in which patients were randomized to 2 versus 1 isocenter for treatment of typical TN. These authors found that pain relief was identical in the 2 groups, but the incidence of facial numbness was higher in patients treated with 2 isocenters. Although facial numbness has been shown to be a strong predictor of pain control in patients with idiopathic $\mathrm{TN}$, this association has not been observed in patients with MS-TN. ${ }^{14,16}$ Weller et al. ${ }^{16}$ found smoking to be a positive predictor of pain control after radiosurgery for MS-TN in their series of 33 patients. Because smoking has effects on the development and progression of MS, these investigators hypothesized that smoking may exacerbate demyelination of the trigeminal nerve enough to cause dysfunction

TABLE 3. Facial numbness outcomes

\begin{tabular}{cc}
\hline BNI Facial Numbness Scale Score & No. of Patients (\%) \\
\hline I & $12(29)$ \\
\hline II & $17(40)$ \\
\hline III & $9(21)$ \\
IV & $4(10)$ \\
\hline
\end{tabular}

in the nerve's pain mechanism. In this same study, neither the size nor the target of the dosimetry was associated with pain control. This finding contrasts with the finding in a radiosurgical series of patients with idiopathic $\mathrm{TN}$ that a more proximal target along the trigeminal nerve was an independent predictor of pain relief. ${ }^{17}$ In our study, no factors, including pre- or postradiosurgical sensory deficit, were predictive of pain control from the index radiosurgery. The inability to identify predictors of pain control may be a function of small sample size and low statistical power. Further research is required to determine whether pain control is associated with dosimetry or facial numbness in MS-TN radiosurgery.

\section{Limitations}

This study represents a retrospective review of GKRS conducted for MS-TN at a single institution and therefore is limited by our methodology. The retrospective nature of this study limits our ability to correlate the degree of MS-TN symptoms and success of treatment with the severity of MS. Another limitation of our study is the lack of in-office clinical follow-up to supplement the survey data, including a more objective measurement of facial sensory outcomes. Additionally, we were unable to contact 8 patients treated during the study period, which could have contributed to follow-up bias.

\section{Conclusions}

In our series of patients with MS-TN, we learned that GKRS offers good short-term pain control for MS-TN but that long-term pain control is uncommon. If the index GKRS fails, salvage GKRS appears to offer beneficial pain control with low rates of bothersome facial numbness. When a multimodal treatment strategy of pain medi- 
cation, radiosurgery, rhizotomy, and MVD is utilized, favorable long-term outcomes can be achieved in patients with MS-TN.

\section{Acknowledgments}

We thank the staff of Neuroscience Publications at BNI for assistance with manuscript preparation.

\section{References}

1. Broggi G, Ferroli P, Franzini A, Nazzi V, Farina L, La Mantia L, et al: Operative findings and outcomes of microvascular decompression for trigeminal neuralgia in 35 patients affected by multiple sclerosis. Neurosurgery 55:830-839, 2004

2. Eller JL, Raslan AM, Burchiel KJ: Trigeminal neuralgia: definition and classification. Neurosurg Focus 18(5):E3, 2005

3. Flickinger JC, Pollock BE, Kondziolka D, Phuong LK, Foote RL, Stafford SL, et al: Does increased nerve length within the treatment volume improve trigeminal neuralgia radiosurgery? A prospective double-blind, randomized study. Int J Radiat Oncol Biol Phys 51:449-454, 2001

4. Hooge JP, Redekop WK: Trigeminal neuralgia in multiple sclerosis. Neurology 45:1294-1296, 1995

5. Huang E, Teh BS, Zeck O, Woo SY, Lu HH, Chiu JK, et al: Gamma knife radiosurgery for treatment of trigeminal neuralgia in multiple sclerosis patients. Stereotact Funct Neurosurg 79:44-50, 2002

6. Kanpolat Y, Berk C, Savas A, Bekar A: Percutaneous controlled radiofrequency rhizotomy in the management of patients with trigeminal neuralgia due to multiple sclerosis. Acta Neurochir (Wien) 142:685-690, 2000

7. Kondziolka D, Lunsford LD, Bissonette DJ: Long-term results after glycerol rhizotomy for multiple sclerosis-related trigeminal neuralgia. Can J Neurol Sci 21:137-140, 1994

8. Little AS, Shetter AG, Shetter ME, Bay C, Rogers CL: Longterm pain response and quality of life in patients with typical trigeminal neuralgia treated with gamma knife stereotactic radiosurgery. Neurosurgery 63:915-924, 2008

9. Mathieu D, Effendi K, Blanchard J, Séguin M: Comparative study of Gamma Knife surgery and percutaneous retrogasserian glycerol rhizotomy for trigeminal neuralgia in patients with multiple sclerosis. J Neurosurg 117 Suppl:175-180, 2012

10. Park KJ, Kondziolka D, Berkowitz O, Kano H, Novotny J Jr, Niranjan A, et al: Repeat gamma knife radiosurgery for trigeminal neuralgia. Neurosurgery 70:295-305, 2012

11. Resnick DK, Jannetta PJ, Lunsford LD, Bissonette DJ: Microvascular decompression for trigeminal neuralgia in patients with multiple sclerosis. Surg Neurol 46:358-362, 1996
12. Rogers CL, Shetter AG, Fiedler JA, Smith KA, Han PP, Speiser BL: Gamma knife radiosurgery for trigeminal neuralgia: the initial experience of The Barrow Neurological Institute. Int J Radiat Oncol Biol Phys 47:1013-1019, 2000

13. Rogers CL, Shetter AG, Ponce FA, Fiedler JA, Smith KA, Speiser BL: Gamma knife radiosurgery for trigeminal neuralgia associated with multiple sclerosis. J Neurosurg 97 (5 Suppl):529-532, 2002

14. Tuleasca C, Carron R, Resseguier N, Donnet A, Roussel P, Gaudart J, et al: Multiple sclerosis-related trigeminal neuralgia: a prospective series of 43 patients treated with gamma knife surgery with more than one year of follow-up. Stereotact Funct Neurosurg 92:203-210, 2014

15. Tuleasca C, Carron R, Resseguier N, Donnet A, Roussel P, Gaudart J, et al: Repeat Gamma Knife surgery for recurrent trigeminal neuralgia: long-term outcomes and systematic review. J Neurosurg 121 Suppl:210-221, 2014

16. Weller M, Marshall K, Lovato JF, Bourland JD, deGuzman AF, Munley MT, et al: Single-institution retrospective series of gamma knife radiosurgery in the treatment of multiple sclerosis-related trigeminal neuralgia: factors that predict efficacy. Stereotact Funct Neurosurg 92:53-58, 2014

17. Xu Z, Schlesinger D, Moldovan K, Przybylowski C, Sun X, Lee CC, et al: Impact of target location on the response of trigeminal neuralgia to stereotactic radiosurgery. J Neurosurg 120:716-724, 2014

18. Zorro O, Lobato-Polo J, Kano H, Flickinger JC, Lunsford LD, Kondziolka D: Gamma knife radiosurgery for multiple sclerosis-related trigeminal neuralgia. Neurology 73:11491154,2009

\section{Disclosures}

Dr. Little is a shareholder in Kogent Surgical.

\section{Author Contributions}

Conception and design: Shetter, Przybylowski, Baranoski, Little, Smith. Acquisition of data: Shetter, Przybylowski. Analysis and interpretation of data: Shetter, Przybylowski, Cole, Smith. Drafting the article: Przybylowski, Baranoski. Critically revising the article: all authors. Reviewed submitted version of manuscript: all authors. Statistical analysis: Cole. Study supervision: Shetter.

\section{Correspondence}

Andrew G. Shetter: Barrow Neurological Institute, St. Joseph's Hospital and Medical Center, Phoenix, AZ. neuropub@ barrowneuro.org. 